\title{
PENGARUH PERSEPSI KEBERMANFAATAN, KEAMANAN, KEPERCAYAAN DAN PERSEPSI KEMUDAHAN PENGGUNAAN TERHADAP PENGGUNAAN ONLINE BANKING PADA MAHASISWA UNIVERSITAS TEKNOLOGI SUMBAWA
}

The Influence of Perception about Usefulness, Safety, Credibility and Perception of Ease Using of Online Banking in Sumbawa University of Technology Student's

\author{
Ririn Nurhayati \\ Program Studi Akuntansi, Fakultas Ekonomi dan Bisnis, Universitas Teknologi \\ Sumbawa \\ E-mail : Ririnnurhayati0859@gmail.com
}

\begin{abstract}
The purpose of this research is to find out: (1) The Influence of Perception about Online Banking Usefulness in Sumbawa University of Technology Student's, (2) The Influence of Online Banking Safety in Sumbawa University of Technology Student's, (3) The Influence of Online Banking Credibility in Sumbawa University of Technology Student's, (4) The Influence of Perception about Online Banking Ease Using in Sumbawa University of Technology Student's, (5) The Influence of Perception about Usefulness, Safety, Credibility and Perception of Ease Using in Simultaneously toward utilizing of Online Banking in Sumbawa University of Technology Student's. This research base on survey. The population in this research is 3500 students in Sumbawa University of Technology (base on student's data in September 2018), and this research take 317 students as the samples. Validity and reability test are using in instrumental test. Regulation analyze test like normality, linearity, multicolinearity, and heteroscedastisity test are do before analyze the data. The hypothesis is tested using multiple linear regression technique. The result of this research is 1) The Influence of Perception about Online Banking Usefulness in Sumbawa University of Technology Student's is positive and significant. 2) The Influence of Online Banking Safety in Sumbawa University of Technology Student's is positive and significant. 3) The Influence of Online Banking Credibility in Sumbawa University of Technology Student's positive and significant. 4) The Influence of Perception about Ease Using of Online Banking in Sumbawa University of Technology Student's is positive and significant. 5) The Influence of Perception about Usefulness, Safety, Credibility and Perception of Ease Using in Simultaneously toward utilizing of Online Banking in Sumbawa University of Technology Student's is positive and significant, caused by $F_{\text {test }}$ value $>F_{\text {table }}\left(F_{\text {test }}=36.344\right.$ and $\left.F_{\text {table }}=2.3719\right)$.
\end{abstract}

Keyword: Perception about Usefulness, Safety, Credibility and Perception of Ease Using of Online Banking 


\section{ABSTRAK}

Penelitian ini bertujuan untuk mengetahui: (1) pengaruh Persepsi Kebermanfaatan terhadap Penggunaan Online banking pada Mahasiswa Universitas Teknologi Sumbawa, (2) Pengaruh Keamanan terhadap Penggunaan Online banking pada Mahasiswa Universitas Teknologi Sumbawa (3) Pengaruh Kepercayaan terhadap Penggunaan Online banking pada Mahasiswa Universitas Teknologi Sumbawa, (4) Pengaruh Persepsi Kemudahan Penggunaan terhadap Penggunaan Online banking pada Mahasiswa Universitas Teknologi Sumbawa, (5) Pengaruh Persepsi Kebermanfaatan, Keamanan, Kepercayaan dan Persepsi Kemudahan Penggunaan secara bersama-sama terhadap Penggunaan Online banking pada Mahasiswa Universitas Teknologi Sumbawa. Penelitian ini termasuk penelitian survei. Populasi dalam penelitian ini adalah Mahasiswa Universitas Teknologi Sumbawa yang berjumlah 3500 orang (data bulan September 2018), sampel yang diambil berjumlah 317 orang. Uji coba instrumen dilakukan dengan uji validitas dan reliabilitas. Sebelum dilakukan analisis terlebih dahulu diadakan pengujian persyaratan analisis meliputi uji normalitas, uji linearitas, uji multikolinearitas, uji heteroskedastisitas. Analisis data yang digunakan untuk menguji hipotesis adalah dengan menggunakan teknik analisis regresi berganda. Hasil penelitian ini menunjukkan bahwa 1) Persepsi Kebermanfaatan berpengaruh positif dan signifikan terhadap Penggunaan Online banking. 2) Keamanan berpengaruh positif dan signifikan terhadap Penggunaan Online banking. 3) Kepercayaan berpengaruh positif dan signifikan terhadap Penggunaan Online banking. 4) Persepsi Kemudahan Penggunaan berpengaruh positif dan signifikan terhadap Penggunaan Online banking. 5) Persepsi Kebermanfaatan, Keamanan, Kepercayaan dan Persepsi Kemudahan Penggunaan secara simultan berpengaruh positif dan signifikan terhadap Penggunaan Online banking pada Mahasiswa Universitas Teknologi Sumbawa, yang ditunjukkan dengan nilai $F$ hitung $>F$ tabel yaitu sebesar $36,344>2,3719$.

Kata Kunci: Persepsi Kebermanfaatan, Keamanan, Kepercayaan, Persepsi Kemudahan Penggunaan, Penggunaan Online banking

\section{PENDAHULUAN}

Indonesia sebagai negara berkembang saat ini memiliki kemajuan teknologi yang canggih dan sangat pesat, peranan teknologi saat ini sangat memberikan banyak pengaruh terutama pada gaya hidup masyarakat saat ini yang selalu ingin mudah dalam melakukan banyak kegiatan, salah satunya ialah hanya dengan menggunakan sebuah teknologi yang mudah dibawa kemanapun masyarakat bisa menggunakan dengan mudah dalam melakukan aktivitas bertransaksi. Perkembangan teknologi yang begitu pesat telah mempengaruhi perkembangan aktivitas baik ekonomi maupun sosial masyarakat, termasuk aktivitas dan transaksi keuangan baik secara langsung maupun tidak langsung. Perkembangan teknologi internet diadopsi oleh industri perbankan untuk meningkatkan pelayanan, peluang ini juga digunakan oleh bank-bank yang ada di Indonesia, baik bank syariah maupun bank konvensional. Perkembangan pelayanan yang dilakukan perbankan berbasis teknologi dalam bentuk online banking saat ini menjadi perhatian utama dan senjata yang revolusioner strategi 
operasional bank untuk menyampaikan maupun untuk persaingan antar bank (Aidi, 2015).

Era persaingan bisnis yang sangat ketat menuntut semua perusahaan untuk lebih agresif dan berani dalam mengambil keputusan serta menerapkan strategi perusahaan sehingga bisa menjadi lebih unggul dalam persaingan dunia usaha dan bisnis bukanlah sebuah hal yang mudah. Strategi merupakan peranan terpenting dalam kunci kesuksesan bagi suatu perusahaan. Salah satunya memanfaatkan teknologi informasi sebagai salah satu strategi perusahaan. Teknologi ini juga mempengaruhi kegiatan pemasaran karena dapat memberikan satu akibat pada kehidupan konsumen, terutama pada hidup dan cara pola konsumsinya (Swastha dan Irawan 2003).

Bank merupakan salah satu perusahaan yang bergerak di bidang jasa. Sistem informasi dan teknologi yang diterapkan di industri perbankan hasilnya sukses dan sangat luar biasa. Salah satu hasil dari kemajuan sistem informasi di bidang perbankan adalah adanya online banking. Pada awalnya online banking digunakan oleh para pebisnis, karna sangat membantu mereka dalam melakukan pekerjaannya, akan tetapi kemajuan teknologi dalam bertransaksi ini pun telah merambah dalam dunia pendidikan, baik kalangan pelajar maupun mahasiswa (Muammar Azizi, 2016).

Universitas Teknologi Sumbawa merupakan salah satu universitas swasta di Sumbawa yang telah menerapkan sistem KTM plus ATM ini. Inovasi ini dilakukan Universitas Tekhnologi Sumbawa dengan menjalin Memorandum of Understanding (MoU) dengan PT. Bank Rakyat Indonesia (BRI) cabang Sumbawa untuk mewujudkan adanya KTM plus ATM di universitas bertujuan untuk memberikan kemudahan dalam mengakses dan memenuhi kebutuhan didalam maupun diluar kampus juga memberikan kenyamanan kepada penggunanya. Mahasiswa sebagai salah satu bagian pelajar yang mempunyai tingkat intelektual yang lebih tinggi tentu ingin mendapatkan fasilitas yang berbeda dalam berbagai hal. Fasilitas ini diberikan untuk mempermudah mahasiswa dalam melakukan proses pembayaran kuliah tiap semester, penerimaan beasiswa, menyimpan tabungan pribadi, bisnis atau kegiatan-kegiatan lain yang berhubungan dengan mahasiswa itu sendiri (http://www.samawarea.com)

Meskipun banyak sekali layanan yang ditawarkan oleh pihak bank kepada nasabah dalam hal ini mahasiswa dengan berbagai kemudahan dan kelebihan dalam melakukan transaksi, tetapi banyak pula mahasiswa yang lebih memilih untuk melakukan transaksi secara langsung ke kantor bank baik kantor bank cabang maupun pusat bank yang bersangkutan. Nasabah/mahasiswa telah merasa nyaman dan terbiasa dalam melakukan transaksi perbankan secara konvensional sehingga belum mengetahui manfaat dari layanan online banking. Hal ini menimbulkan sudut pandang yang berbeda dalam persepsi manfaat yang diterima nasabah melalui layanan online banking. Pada dasarnya, sebuah layanan yang mampu memberikan manfaat pada nasasbah pasti akan diterima dengan baik. Semakin nasabah merasa online banking bermanfaat maka online banking semakin sering digunakan. Begitu juga sebaliknya, apabila nasabah menganggap online banking kurang bermanfaat, maka nasabah cenderung tidak mau menggunakan jasa online banking tersebut (Cahyo, 2013). Berdasarkan penjelasan diatas maka dalam hal ini termasuk mahasiswa Universitas Teknologi Sumbawa yang masih melakukan layanan perbankan dengan mengunjungi kantor bank secara langsung untuk melakukan transaksi. 
Keengganan mahasiswa untuk menggunakan layanan online banking tentunya dipengaruhi dari berbagai faktor diantaranya seperti kepercayaan, kebermanfaatan dan tingkat keamanan layanan. Berbagai kasus yang terjadi yaitu, pada saat ingin menggunakan layanan online banking tiba-tiba saldo di rekening berkurang dengan sndirinya, adapun berbagai jebakan kartu, pembobolan melalui skimming EDC (Electronic Data Capture), penipuan melalui e-banking dengan modus nasabah dinyatakan menang undian berhadiah dan masih banyak kasus-kasus lainnya (Reipita Sari, 2013). Adanya tindakan kejahatan seperti ini bisa menimbulkan keraguan atau ketidak percayaan nasabah terhadap layanan perbankan.

Faktor kepercayaan merupakan faktor yang memberi pengaruh terhadap penerimaan online banking sehingga bank harus membentuk sikap positif yang dapat meningkatkan kepercayaan pelanggan terhadap teknologi yang diterapkan (Tjini dan Baridwan, 2011). Ketika suatu bank dapat memberikan keamanan bagi nasabahnya maka kepercayaan akan diperoleh dari penggunanya.

Kemudahan penggunaan mampu mengurangi usaha seseorang baik dalam segi waktu maupun tenaga untuk mempelajari sistem atau teknologi karena individu yakin bahwa sistem tersebut mudah untuk dipahami. Intensitas penggunaan dan interaksi antara pengguna (user) dengan sistem juga dapat menunjukkan kemudahan penggunaan. Sistem yang lebih sering digunakan menunjukkan bahwa sistem tersebut lebih dikenal, lebih mudah dioperasikan dan lebih mudah digunakan oleh penggunanya (Cahaya, 2014).

Dari beberapa alasan yang telah didapatkan tentunya mahasiswa memiliki kriteria yang dijadikan suatu pertimbangan dalam memilih suatu layanan jasa perbankan yang akan nasabah gunakan. Kriteria inipun tidak lepas dari besarnya manfaat layanan yang mampu dirasakan oleh nasabah itu sendiri. Beberapa penelitian investigasi layanan jasa perbankan tersebut atas dasar penerimaan nasabah terhadap penggunaan teknologi telah dilakukan melalui perluasan teori Technology Acceptance Model (TAM). TAM merupakan yang pertama kali diperkenakan oleh Davis (1989) mengemukakan bahwa persepsi nasabah atas persepsi kebermanfaatan dan persepsi kemudahan penggunaan adalah faktor utama yang mempengaruhi segi penggunaan atau pengadosian teknologi.

Berdasarkan latar belakang diatas, dalam upaya meningkatkan kualitas pelayanan pada online banking disuatu bank maka bank perlu mengetahui berbagai faktor yang mempengaruhi nasabah untuk menggunakan online banking. Maka dari itu penelitian ini membahas permasalahan tersebut dengan judul: "Pengaruh Persepsi Kebermanfaatan, Keamanan, Kepercayaan dan Persepsi Kemudahan Penggunaan terhadap Penggunaan Online Banking pada Mahasiswa Universitas Teknologi Sumbawa”.

Berdasarkan penejelasan di atas, maka dapat di rumuskan tujuan penelitian sebagai berikut:

1. Mengetahui pengaruh Persepsi Kebermanfaatan terhadap penggunaan Online Banking pada Mahasiswa Universitas Teknologi Sumbawa.

2. Mengetahui pengaruh Keamanan terhadap Penggunaan Online Banking pada mahasiswa Universitas Teknologi Sumbawa.

3. Mengetahui pengaruh Kepercayaan terhadap Penggunaan Online Banking pada Mahasiswa Universitas Teknologi Sumbawa. 
4. Mengetahui pengaruh Persepsi Kemudahan Penggunaan terhadap penggunaan Online Banking pada Mahasiswa Universitas Teknologi Sumbawa.

5. Mengetahui pengaruh Persepsi Kebermanfaatan, Keamanan, Kepercayaan, dan Persepsi Kemudahan Penggunaaan secara bersama-sama terhadap penggunaan Online Banking pada Mahasiswa Universitas Teknologi Sumbawa.

\section{Metode Penelitian}

Penelitian ini merupakan jenis penelitian yang menggunakan metode penelitian kuantitatif asosiatif. Penelitian ini bertujuan untuk mengetahui apakah variabel (x) berpengaruh terhadap variabel (y). Penelitian ini termasuk dalam penelitian survei. Metode suvei digunakan untuk mendapatkan data dari tempat tertentu yang menggambarkan suatu variabel dan kejadian yang sebenarnya serta apa adanya dengan memberikan atau menyebarkan angket/kuisioner terstruktur kepada mahasiswa Universitas Teknologi Sumbawa. Data yang digunakan dalam penelitian ini adalah data primer. Dalam penelitian ini sumber diperoleh dari kuisioner yang disebarkan kepada mahasiswa aktif Universitas Teknologi Sumbawa yang memiliki KTM plus ATM dan menggunakan online banking sebagai responden dengan secara langsung.

\section{Lokasi Peneitian}

Penelitian ini dilakukan di Universitas Teknologi Sumbawa yang berlokasi di dusun Batu Alang kecamatan Moyo Hulu, Sumbawa Nusa Tenggara Barat.

\section{Waktu Pelaksanaan}

Penelitian awal dilaksanakan pada 27 November 2018 hingga 21 Desember 2018.

\section{Variabel}

Menurut Sugiyono (2010), variabel merupakan suatu atribut atau sfat atau nilai dari orang, objek, atau kegiatan yang mempunyai variasi tertentu yang ditetapkan oleh peneliti untuk dipelajari dan ditarik kesimpulanya. Adapun variabel penelitian diambil dari teori tentang pengadopsian teknologi, yaitu: (1) penggunaan,

(2) persepsi kebermanfaatan,

penggunaan, kepercayaan.

(3) kemudahan keamanan,

\section{Populasi dan Sampel}

Populasi dalam penelitian ini adalah seluruh mahasiswa aktif di Universitas Tekhnologi Sumbawa yang memiliki KTM plus ATM dan menggunakannya melalui online banking. Populasi yang digunakan sebesar 3500 mahasiswa aktif Universitas Tekhnologi Sumbawa yang terdiri dari 6 Fakultas, yakni: Fakultas Teknik, Fakultas Teknobiologi, Fakultas Ekonomi dan Bisnis, Fakultas Teknologi Pertanian, Fakultas Ilmu Komunikasi dan Fakultas Psikologi, serta memiliki 15 program studi (Prodi), yakni: Prodi Teknik Metalurgi dan Material, Prodi Teknik Mesin, Prodi Teknik Industri, Prodi Teknik Elektro, Prodi Teknik Sipil, Prodi Informatika, Prodi Manajemen, Prodi Ekonomi Pembangunan, Prodi Akuntansi, Prodi Manajemen Inovasi, Prodi Teknologi Hasil Pertanian, Prodi Teknologi Industri Pertanian, Prodi Ilmu Komunikasi, Prodi Psikologi (https//www.uts.ac.id/sejarahuniversitas-teknologi-sumbawa/). Sampel terdiri atas sejumlah anggota yang dipilih dari populasi. Sampel dalam penelitian ini menggunakan teknik proportional random sampling. Jadi sampel dalam penelitian ini berjumlah 317 responden mahasiswa aktif Universitas Teknologi Sumbawa dengan taraf kesalahan $5 \%$. 
Hasil dan Pembahasan Uji Validitas

Sebelum data yang dikumpulkan, diolah dan di analisis lebih lanjut, maka diperlukan uji Validitas. Validitas suatu instrumen menunjukkan suatu alat ukur yang dapat mengukur sejauh mana kebenaran alat itu untuk mengukur sesuatu yang diperlukan, atau seberapa keasliannya (Mardalis, 2009). Teknik yang digunakan untuk uji validitas pada penelitian ini adalah membandingkan antara nilai $r_{\text {hitung }}$ dengan nilai $r_{\text {tabel }}$ dengan taraf signifikan 0,05. Jika $r_{\text {hitung }} \geq r_{\text {tabel }}$ (dengan sig. 0,05) maka instrumen atau item-item pertanyaan berkorelasi signifikan terhadap skor total (dinyatakan valid).

Tabel 1. Hasil Uji Validitas Penggunaan Online Banking

\begin{tabular}{|c|c|c|c|}
\hline $\begin{array}{c}\text { No } \\
\text { Butir }\end{array}$ & $\begin{array}{c}\mathrm{r} \\
\text { hitung }\end{array}$ & $\begin{array}{c}\mathrm{r} \\
\text { tabel }\end{array}$ & $\begin{array}{c}\text { Keteranga } \\
\mathrm{n}\end{array}$ \\
\hline 1 & 0,704 & 0,361 & Valid \\
2 & 0,577 & 0,361 & Valid \\
3 & 0,620 & 0,361 & Valid \\
4 & 0,538 & 0,361 & Valid \\
5 & 0,727 & 0,361 & Valid \\
6 & 0,697 & 0,361 & Valid \\
7 & 0,586 & 0,361 & Valid \\
8 & 0,563 & 0,361 & Valid \\
\hline
\end{tabular}

Sumber: data primer yang diolah 2018

Tabel 2. Hasil Uji Validitas Persepsi Kebermanfaatan

\begin{tabular}{|c|c|c|c|}
\hline $\begin{array}{c}\text { No } \\
\text { Butir }\end{array}$ & $\begin{array}{c}\mathrm{r} \\
\text { hitung }\end{array}$ & $\begin{array}{c}\mathrm{r} \\
\text { tabel }\end{array}$ & Keterangan \\
\hline 1 & 0,716 & 0,361 & Valid \\
2 & 0,829 & 0,361 & Valid \\
3 & 0,687 & 0,361 & Valid \\
4 & 0,770 & 0,361 & Valid \\
5 & 0,824 & 0,361 & Valid \\
6 & 0,780 & 0,361 & Valid \\
7 & 0,716 & 0,361 & Valid \\
8 & 0,676 & 0,361 & Valid \\
9 & 0,736 & 0,361 & Valid \\
10 & 0,708 & 0,361 & Valid \\
11 & 0,808 & 0,361 & Valid \\
\hline
\end{tabular}

Sumber: data primer yang diolah 2018

Tabel 3. Hasil Uji Validitas Keamanan

\begin{tabular}{|c|c|c|c|}
\hline $\begin{array}{c}\text { No } \\
\text { Butir }\end{array}$ & $\begin{array}{c}\mathrm{r} \\
\text { hitung }\end{array}$ & $\begin{array}{c}\mathrm{r} \\
\text { tabel }\end{array}$ & Keterangan \\
\hline 1 & 0,717 & 0,361 & Valid \\
2 & 0,710 & 0,361 & Valid \\
3 & 0,875 & 0,361 & Valid \\
4 & 0,858 & 0,361 & Valid \\
5 & 0,827 & 0,361 & Valid \\
6 & 0,911 & 0,361 & Valid \\
\hline
\end{tabular}

Sumber: data primer yang diolah 2018

Tabel 4. Hasil Uji Validitas Kepercayaan

\begin{tabular}{|c|c|c|c|}
\hline $\begin{array}{c}\text { No } \\
\text { Butir }\end{array}$ & $\begin{array}{c}\mathrm{r} \\
\text { hitung }\end{array}$ & $\begin{array}{c}\mathrm{r} \\
\text { tabel }\end{array}$ & Keterangan \\
\hline 1 & 0,652 & 0,361 & Valid \\
2 & 0,837 & 0,361 & Valid \\
3 & 0,772 & 0,361 & Valid \\
4 & 0,775 & 0,361 & Valid \\
5 & 0,833 & 0,361 & Valid \\
6 & 0,743 & 0,361 & Valid \\
\hline
\end{tabular}

Sumber: data primer yang diolah 2018

Tabel 5. Hasil uji Validitas Kemudahan Penggunaan

\begin{tabular}{|c|c|c|c|}
\hline $\begin{array}{c}\text { No } \\
\text { Butir }\end{array}$ & $\begin{array}{c}\mathrm{r} \\
\text { hitung }\end{array}$ & $\begin{array}{c}\mathrm{r} \\
\text { tabel }\end{array}$ & Keterangan \\
\hline 1 & 0,858 & 0,361 & Valid \\
2 & 0,868 & 0,361 & Valid \\
3 & 0,833 & 0,361 & Valid \\
4 & 0,810 & 0,361 & Valid \\
5 & 0,937 & 0,361 & Valid \\
6 & 0,937 & 0,361 & Valid \\
7 & 0,929 & 0,361 & Valid \\
8 & 0,955 & 0,361 & Valid \\
9 & 0,879 & 0,361 & Valid \\
10 & 0,879 & 0,361 & Valid \\
11 & 0,919 & 0,361 & Valid \\
\hline
\end{tabular}

Sumber: data primer yang diolah 2018

\section{Uji Reliabilitas}

Reliabilitas atau keterandalan suatu instrumen sebagai alat ukur dimaksudkan untuk mengetahui sejauh 
mana kebenaran alat ukur tersebut cocok digunakan sebagai alat ukur untuk mengukurnya sesuatu (Mardalis, 2009).

Tabel 6. Hasil Uji Reliabilitas

\begin{tabular}{|c|l|c|c|}
\hline No & \multicolumn{1}{|c|}{ Variabel } & $\begin{array}{c}\text { Cronba } \\
\text { ch } \\
\text { alpha }\end{array}$ & $\begin{array}{l}\text { Keterang } \\
\text { an }\end{array}$ \\
\hline 1 & $\begin{array}{l}\text { Penggunaan } \\
\text { Online Banking }\end{array}$ & 0,742 & Reliabel \\
2 & $\begin{array}{l}\text { Persepsi } \\
\text { Kebermanfaata }\end{array}$ & 0,772 & Reliabel \\
& $\mathrm{n}$ & & \\
3 & Keamanan & 0,802 & Reliabel \\
4 & Kepercayaan & 0,788 & Reliabel \\
5 & Kemudahan & 0,786 & Reliabel \\
& Penggunaan & & \\
\hline
\end{tabular}

Sumber: data primer yang diolah 2018

\section{Uji Asumsi Klasik}

\section{Uji Normalitas}

Uji Normalitas digunakan untuk menguji apakah dalam model regresi dari kedua variabel (variabel dependen dan variabel independen) yang kita pakai mempunyai distribusi normal atau tidak. Sebuah data penelitan yang baik adalah yang datanya berdistribusi normal (Bawono, 2006).

Tabel 7. Hasil Uji Normalitas

One-Sample Kolmogorov-Smirnov Test

\begin{tabular}{|ll|r|}
\hline & & $\begin{array}{r}\text { Unstanda } \\
\text { rdized } \\
\text { Residual }\end{array}$ \\
\hline $\mathrm{N}$ & Mean & 317 \\
Normal & Std. & OE-7 \\
Parametersa,b & Deviation & 3.277475 \\
& Absolute & .036 \\
Most Extreme & Positive & .026 \\
Differences & Negative & -.036 \\
Kolmogorov-Smirnov Z & .642 \\
Asymp. Sig. (2-tailed) & .804 \\
\hline
\end{tabular}

a. Test distribution is Normal.

b. Calculated from data.

Sumber: data primer yang diolah 2018

\section{Uji Multikolinieritas}

Uji Multikonolinieritas bertujuan untuk mengetahui apakah terdapat gejala korelasi antara variabel independen yang satu dengan variabel independen yang lain. Menurut Ghazali (2011) ada tidaknya multikolinieritas dapat dilihat dari besarnya Variance Inflation Factor (VIF) dan nilai Tolerance Value. Yaitu jika besaran $\mathrm{VIF}<10$ dan tolerance $>0,10$ maka tidak terjadi multikolinieritas.

Tabel 8. Hasil Uji Multikolinieritas

\begin{tabular}{|l|c|c|c|}
\hline \multicolumn{1}{|c|}{ Variabel } & $\begin{array}{c}\text { Toler } \\
\text { ance }\end{array}$ & VIF & Keterangan \\
\hline $\begin{array}{l}\text { Persepsi } \\
\text { Kebermanfaatan }\end{array}$ & 0,908 & 1,101 & $\begin{array}{c}\text { Tidak terjadi } \\
\text { multikolinier } \\
\text { itas }\end{array}$ \\
\hline Keamanan & 0,890 & 1,123 & $\begin{array}{c}\text { Tidak terjadi } \\
\text { multikolinier } \\
\text { itas }\end{array}$ \\
\hline Kepercayaan & 0,938 & 1,066 & $\begin{array}{c}\text { Tidak } \\
\text { terjadi } \\
\text { multikolini } \\
\text { eritas }\end{array}$ \\
\hline $\begin{array}{l}\text { Persepsi } \\
\text { Kemudahan } \\
\text { Penggunaan }\end{array}$ & 0,896 & 1,116 & $\begin{array}{c}\text { Tidak terjadi } \\
\text { multikolinier } \\
\text { itas }\end{array}$ \\
\hline
\end{tabular}

Sumber: data primer yang diolah 2018

\section{Uji Heteroskedastisitas}

Uji Heteroskedastisitas menunjukan bahwa varian variabel tidak sama untuk semua pengamatan/observasi (Wijaya, 2009).

Tabel 9. Hasil Uji Heteroskedastisitas

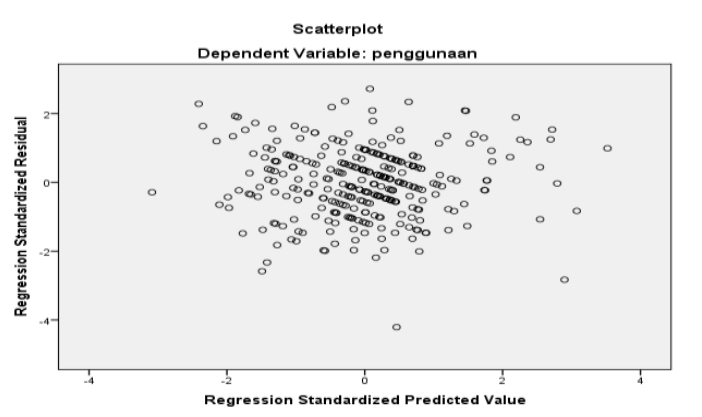

Sumber: data primer yang diolah 2018 
Gambar tersebut menunjukkan bahwa penyebaran titik-titik yang ditimbulkan terbentuk secara acak. Dengan demikian dapat disimpulkan tidak terjadi gejala heteroskedastisitas.

\section{Uji Linieritas}

Pengujian Linieritas digunakan untuk menguji apakah spesifikasi model yang kita gunakan sudah tepat atau lebih baik dalam spesifikasi model bentuk lain, spesifikasi model dapat berupa linier, kuadrat atau kubik (Bawono, 2006).

Tabel 10. Hasil Uji Linieritas

\begin{tabular}{|l|c|c|}
\hline \multicolumn{1}{|c|}{ Variabel } & Linearity & Keterangan \\
\hline Kebermanfaatan & 0,000 & Linear \\
\hline Keamanan & 0,000 & Linear \\
\hline Kepercayaan & 0,000 & Linear \\
\hline $\begin{array}{l}\text { Persepsi Kemudahan } \\
\text { Penggunaan }\end{array}$ & 0,000 & Linear \\
\hline
\end{tabular}

Sumber: data primer yang diolah 2018

\section{Analisis Regresi Berganda}

\section{Pengujian Hipotesis}

Pengujian terhadap hipotesis yang diajukan dalam penelitian ini menggunakan analisis regresi linier. Pengujian hipotesis kelima variabel menggunakan analisis regresi linier berganda karena menjelaskan pengaruh empat variabel bebas secara simultan dengan satu variabel terikat.

\section{a. Uji $\mathbf{t}_{\text {test }}$}

Uji ini digunakan untuk melihat tingkat signifikan variabel independen mempengaruhi variabel dependen secara individu atau sendiri-sendiri. Pengujian ini dilakukan secara parsial atau individu, dengan menggunakan uji $t$ statistik untuk masing-masing variabel bebas, dengan tingkat kepercayaan tertentu (Bawono, 2006). Hasil uji test dapat dilihat dibawah ini:

Tabel 11. Hasil Uji test

\section{Coefficients $^{\mathrm{a}}$}

\begin{tabular}{|l|r|r|r|r|r|}
\hline \multirow{2}{*}{ Model } & \multicolumn{2}{|c|}{$\begin{array}{c}\text { Unstandardized } \\
\text { Coefficients }\end{array}$} & $\begin{array}{c}\text { Standardized } \\
\text { Coefficients }\end{array}$ & \multirow{2}{*}{ T } & \multirow{2}{*}{ Sig. } \\
\cline { 2 - 5 } & \multicolumn{1}{c|}{$\mathrm{B}$} & Std. Error & \multicolumn{1}{c|}{ Beta } & & \\
\hline $\begin{array}{l}\text { (Constant) } \\
\text { Kebermanfa } \\
\text { atan }\end{array}$ & 4.035 & 2.154 & & 1.873 & .062 \\
$\begin{array}{l}\text { keamanan } \\
\text { Kepercayaa }\end{array}$ & .153 & .028 & .267 & 5.446 & .000 \\
$\mathrm{n}$ & .266 & .069 & .204 & 4.125 & .000 \\
kemudahan & .142 & .031 & .185 & 3.841 & .000 \\
\hline
\end{tabular}

a. Dependent Variable: penggunaan

Dari tabel coefficient, dapat dibuat model persamaan regresi sebagai berikut:

$$
\begin{aligned}
& Y=\beta_{0}+\beta_{1} X_{1}+\beta_{2} X_{2}+\beta_{3} X_{3}+\beta_{4} X_{4} \\
& Y=4.035+0.153 X 1+0.292 X 2+0.266 X 3 \\
& +0.142 X 4
\end{aligned}
$$

Dimana:

$$
\begin{aligned}
\mathrm{Y} & =\text { Penggunaan Online Banking } \\
\mathrm{X} 1 & =\text { Persepsi Kebermanfaatan } \\
\mathrm{X} 2 & =\text { Keamanan } \\
\mathrm{X} 3 & =\text { Kepercayaan } \\
\mathrm{X} 4 & =\text { Kemudahan Penggunaan }
\end{aligned}
$$

Apabila nilai signifikansi kurang dari nilai alfa 0.05 maka variabel tersebut dinyatakan positif mempengaruhi variabel dependennya. Berdasarkan hasil uji $\mathrm{t}$, peneliti mendapatkan nilai $\mathrm{t}$ hitung masing-masing untuk persepsi kemudahan (X1), persepsi kebermanfaatan (X2) keamanan (X3) kepercayaan (X4) kemudahan penggunaan yaitu: 
1. Pengaruh Persepsi Kebermanfaatan terhadap Penggunaan Online Banking Variabel persepsi kebermanfaatan (X1) dengan t hitung 5.446 dan signifikansi 0.000 , dimana nilai signifikansi lebih kecil dari nilai alfa 0.05 maka dapat dikatakan bahwa variabel persepsi kebermanfaatan (X1) secara statistik berpengaruh positif dan signifikan terhadap penggunaan online banking pada mahasiswa Universitas Teknologi Sumbawa (Y).

2. Pengaruh Keamanan terhadap Penggunaan Online Banking

Variabel keamanan (X2) dengan t hitung 4.125 dan signifikansi 0.000 , dimana nilai signifikansi lebih lebih kecil dari nilai alfa 0.05 maka dapat dikatakan bahwa variabel keamanan (X2) secara statistik berpengaruh positif dan signifikan terhadap penggunaan online banking pada mahasiswa Universitas Teknologi Sumbawa (Y).

3. Pengaruh Persepsi Kepercayaan terhadap Penggunaan Online Banking Variabel kepercayaan (X3) dengan $t$ hitung 3.841 dan signifikansi 0.000 dimana nilai signifikansi lebih lebih kecil dari nilai alfa 0.05 maka dapat dikatakan bahwa variabel kepercayaan (X3) secara statistik berpengaruh positif dan signifikan terhadap penggunaan online banking pada mahasiswa Universitas Teknologi Sumbawa (Y).

4. Pengaruh Persepsi Kemudahan Penggunaan terhadap Penggunaan Online Banking

Variabel kemudahan penggunaan (X4) dengan t hitung 4.660 dan signifikansi 0.000 dimana nilai signifikansi lebih lebih kecil dari nilai alfa 0.05 maka dapat dikatakan bahwa variabel kemudahan penggunaan (X4) secara statistik berpengaruh positif dan signifikan terhadap penggunaan online banking pada mahasiswa Universitas Teknologi Sumbawa (Y).

\section{b. Uji F test}

Uji $F_{\text {test }}$ dilakukan untuk mengatur seberapa jauh variabel independen secara bersama-sama mempengaruhi variabel independen. Uji $F_{\text {test }}$ dapat dilihat pada tabel berikut:

Tabel 10. Hasil Uji $F_{\text {test }}$

\section{ANOVAa}

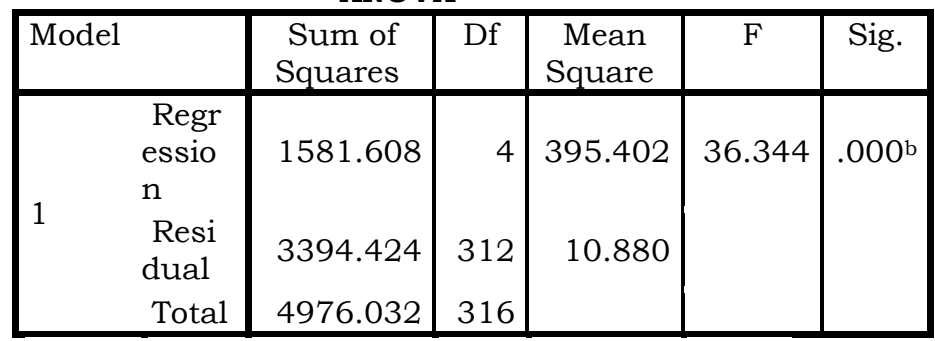

a. Dependent Variable: penggunaan

b. Predictors: (Constant), kemudahan, kepercayaan, kebermanfaatan, keamanan

\section{c. $\mathbf{U j i} \mathbf{R}^{2}$}

Menurut Bawono (2006), koefisien determinasi $\left(\mathrm{R}^{2}\right)$ menunjukkan sejauh mana tingkat hubungan antara variabel dependen dengan variabel independen atau sejauh mana kontribusi variabel independen mempengaruhi variabel dependen.

Tabel 11. Hasil uji $\mathrm{R}^{2}$

\begin{tabular}{|l|c|c|r|c|}
\hline $\begin{array}{l}\text { Mod } \\
\text { el }\end{array}$ & $\mathrm{R}$ & $\begin{array}{c}\mathrm{R} \\
\text { Squa } \\
\text { re }\end{array}$ & $\begin{array}{c}\text { Adjuste } \\
\mathrm{d} \mathrm{R} \\
\text { Square }\end{array}$ & $\begin{array}{c}\text { Std. Error } \\
\text { of the } \\
\text { Estimate }\end{array}$ \\
\hline 1 & $\begin{array}{r}.56 \\
4 \mathrm{a}\end{array}$ & .318 & .309 & 3.29842 \\
\hline
\end{tabular}

a. Predictors: (Constant), kemudahan, kepercayaan, kebermanfaatan, keamanan 
Tabel diatas menjelaskan bahwa koefisien adjusted $R$ square sebesar 0,309 ini berarti kontribusi variabel independen (persepsi kebermanfaatan, keamanan, kepercayaan, kemudahan penggunaan) mampu menjelaskan variabel dependen (penggunaan online banking) sebesar $30,9 \%$ sedangkan sisanya sebesar $69,1 \%$ dijelaskan oleh variabel lain diluar model ini.

\section{Kesimpulan}

Berdasarkan hasil penelitian dapat disimpulkan bahwa variabel persepsi kebermanfaatan berpengaruh positif dan signifikan terhadap penggunaan Online Banking pada mahasiswa Universitas Teknologi Sumbawa. Adapun variabel keamanan berpengaruh positif dan signifikan terhadap penggunaan Online Banking pada mahasiswa Universitas Teknologi Sumbawa. Variabel kepercayaan berpengaruh positif dan signifikan terhadap penggunaan Online Banking pada mahasiswa Universitas Teknologi Sumbawa. Selanjutnya variabel kemudahan Penggunaan berpengaruh positif dan signifikan terhadap penggunaan Online Banking pada mahasiswa Universitas Teknologi Sumbawa. Secara simultan, Persepsi Kebermanfaatan, keamanan, kepercayaan dan persepsi Kemudahan Penggunaan secara bersama-sama berpengaruh positif dan signifikan terhadap terhadap penggunaan online banking pada mahasiswa Universitas Teknologi Sumbawa. Berdasarakan hasil dari nilai adjusted $R$ square $\left(R^{2}\right)$ yang diperoleh bernilai positif yaitu mempengaruhi 30,9\% perubahan pada Penggunaan Online banking, sedangkan sisanya sebesar 69,1\% dipengaruhi oleh variabel lain di luar penelitian ini.

Berdasarkan kesimpulan tersebut, penulis menyarankan kepada Manajer bank diharapkan untuk selalu memperbaharui perawatan maupun ketahanan (maintenance) sistem online banking yang digunakan baik dari segi pelayanan, sistem transaksi, tampilan, fitur dan memperbarui fasilitas-fasilitas lainnya agar semakin memberikan manfaat langsung, mengurangi tingkat kesulitan maupun kerumitan dalam segi transaksi dan dapat mempermudah dalam melakukan transaksi menggunakan online banking.

Bagi pemerintah sebaiknya pemerintah mengeluarkan kebijakan untuk menarik masyarakat untuk menabung dan menggunakan suatu layanan perbankan sehingga dengan tingginya minat masyarakat untuk menabung maka akan memberikan dampak bagi kreditor sektor swasta sehingga pertumbuhan ekonomi dapat berjalan dengan baik.

\section{Daftar Pustaka}

Azizi, M. (2016). Pengaruh Persepsi Kemudahan, Kepercayaan dan risiko terhadap Keputusan Nasabah Menggunakan E-Banking pada PT.Bank BNI Syariah KV Yogyakarta. Skripsi.

Sugiyono. (2010). Metode Penelitian Kuantitatif Kualitatif dan $R \& D$. Bandung: Alfabeta.

Yoso, W. (2014). Pengaruh Persepsi Kebermanfaatan, Keamanan, Kepercayaan dan Persepsi Kemudahan Penggunaan terhadap Penggunaan Online Banking pada mahasiswa s1 Fakultas Ekonomi dan Bisnis Universitas Negeri Yogyakarta. skripsi.

Davis F. D. (1989). perceived usefulnes, perceived ease of use, and user acceptance of information technology. MIS quartely, 319-340. 
Davis, F. (1983). perceived Usefulness, Perceived Ease Of use, and Acceptance of Information System Technology. MIS Quarerly, 319339.

Mardalis. (2009). Populasi dan Sampel Penelitian. Retrieved from http:// triatra.wordpress.com.

Bawono Anton. (2006). Multivariate Analyze dengan SPSS. Salatiga: Stain Salatiga Press.

Imam, G. (2011). Aplikasi Analisis Multivariate dengan program SPSS. Semarang: Badan Penerbit Universitas Diponegoro.

Suranto A.W. (2010). Tinjauan Tentang Persepsi Siswa. Retrieved from http://eprints.UNY.ac.id_Artikel_Il miah.pdf.

Baridwan Zaki. (2011). Intermediate Accounting. Yogyakarta: BPFE.

Mayer R.C., Davis, J. H., \& Schoorman, F.D. (1995). An Integratif Model of Organizational Trust. Academy of Management Review.

Miftah Toha. (2003). Perilaku Organisasi Konsep Dasar dan Aplikasinya. Jakarta: Grafindo Persada.

Muasyaroh, Heni Husnni. (2014). Pengaruh bauran Pemasaran terhadap Minat Nasabah Menggunakan E-Banking PT BNI Syariah Yogyakarta". skripsi. Fakultas Syariah dan Hukum Universitas Islam Negeri Yogyakarta.

Noviandini, N. C. (2012). Pengaruh persepsi Kebermanfaatan, Persepsi kemudahan, Penggunaan dan Kepuasan wajib Pajk terhadap penggunaaan E-filling bagi wajib pajak terhadap penggunaan Efilling bagi wajib pajak di Yogyakarta. S1 thesis Universitas Negeri Yogyakarta.

Pikkarainen T., PikkarainenK., Karjaluato H., Pahnila, S. (2004). Internet Research. Retrieved from Consumer Acceptance of Online Banking: An Extension of the Technology Acceptance Model.

Pratiwi Devvy Pisheila. (2012). Pengaruh Persepsi Manfaat, Persepsi kemudahan Penggunaan dan pengalaman terhadap Penggunaan Mobile Banking. http://katalog.library.perbanas.ac. id.

http://www.samawarea.com akses 28

Desember 2018

http://www.uts.ac.id sejarah universitas-teknologi-sumbawa 